\title{
An Integrated Approach to the World Cup Teams Using Entropy based ARAS and SAW Methods
}

\author{
Fazıl Gökgöz and Engin Yalçın
}

\begin{abstract}
Football is a highly significant branch for people dealing with sport. Multi-criteria decision making (MCDM) methods enable decision-makers to rank and compare among alternatives. World Cup is organized by a different country within every 4 year and it is the most important tournament on national football team basis. MCDM methods enable decision makers to judge many conflicting area. In analyzing football teams, many different criterions should be considered. Therefore, MCDM methods are logical vehicles to evaluate teams. This study aims to evaluate the national teams in 2018 World Cup. We compare two widely used MCDM methods namely, additive ratio assessment (ARAS) and simple additive weighting (SAW) method. We integrate these methods with Shannon entropy approach which is an objective approach to determine the weights of criteria. The criterions we used in this study are attempts on target, accurate pass percentage, possession percentage and total goals. According to results of this study, there is a significant harmony among these two methods. Belgium has found the most successful team for both methods. Belgium is followed by Croatia for both methods. Titleholder France has found as the third team on the basis of ARAS method. Besides, England has found as the third team in SAW method. In this framework, our empirical results are in line with performances of the World Cup teams in the field. We may conclude that this empirical study reveals significant results for decision makers in analyzing the football teams.
\end{abstract}

Keywords - Football, Multi-Criteria Decision Making, Ranking, World Cup.

\section{INTRODUCTION}

Football is a highly remarkable team sport in the world. Football has the highest television audience as well. In the literature, so far there have been many papers devoted to football efficiency. However, to the best of our knowledge, there are not many studies applied Multi Criteria Decision Making (MCDM) to football research.

In today's tough and complex situations, it would not be wise to make decisions depending on single criteria. Due to this reason, when decision-making involves many conflicting criteria MCDM methods enable decision-makers to judge better [1]. MCDM methods are generally employed to rank and evaluate many decision-making units with conflicting criteria. Evaluation of football teams is significant since ranking scores reveals important indicators for both officials and individual decision makers.

Fazıl Gökgöz, Professor, Ankara University, Faculty of Political Sciences, Ankara-Turkey.

Engin Yalçın, Ph.D Student, Ankara University, Faculty of Political Sciences, Ankara-Turkey.
In this study, an integrated approach has adopted. At first, we utilize Shannon entropy method to compute the weights of criteria and we employ additive ratio assessment (ARAS) and simple additive weighting (SAW) methods to rank alternatives later. The remainder of this paper continues in that way. In the next part, we mention a brief literature review regarding the methods. Then, we introduce Shannon entropy method, additive ratio analysis method and simple additive weighting method. In the last section, we illustrate the proposed approach with an empirical analysis.

\section{LITERATURE REVIEW}

There are numerous studies performed by Shannon entropy and additive ratio assessment and simple additive weighting methods. Some of them are as follows: Reference [16] adopted a two-stage method. In their study, they firstly introduced entropy method to weight 35 criteria then they line up tourism destination by TOPSIS method. Reference [2] introduced an integrated Entropy and fuzzy TOPSIS approach to weight the criteria and then determine the supplier. Reference [4] utilize Shannon entropy with PROMETHEE method to evaluate Indian university websites. Reference [3] uses AHP and ARAS methodology to determine the most suitable catering supplier. Reference [7] introduces an integrated approach to evaluate cloud computing vendors. The proposed method integrates four methods namely statistical variance, simple additive weighting (SAW), TOPSIS and Delphi-AHP. Reference [11] applies data envelopment analysis (DEA) and SAW methods to compare power plants. Reference [15] applies additive ratio assessment method to installment alternative selection. Reference [6] utilizes ARAS method to evaluate important factors for preservation of historic buildings. Reference [9] applies TOPSIS method to assess football players' performance.

\section{METHOD}

\section{A. Shannon Entropy}

There are various methods to calculate weight for MCDM problems and Shannon entropy method is one of them. Shannon entropy method is able to tackle with subjective shortcoming of subjective weighting methods [12]. Assume that there are $\mathrm{m}$ alternatives to appraise $\mathrm{n}$ criteria. $\left(x_{i j}\right)_{m * n}$ is the first decision matrix. The decision matrix can be normalized as follows [8].

$$
p_{i j}=x_{i j} / \sum_{i=1}^{m} x_{i j}
$$

The information entropy for every index is revealed as:

$$
E_{j}=-(\ln m)^{-1} \sum_{i=1}^{m} p_{i j} \ln p_{i j}
$$


and the weight acquired from entropy method is revealed as follows:

$w_{j}=\left(1-E_{j}\right) /\left(n-\sum_{j=1}^{n} E_{j}\right)$

where $0 \leq w_{j} \leq 1$ and $\sum_{j=1} w_{j}=1$

The principal benefit of entropy method is that it is easy to use and it has a high discriminatory power [5].

\section{B. Additive ratio assessment (ARAS) Method}

Reference [14] firstly developed ARAS method. The steps of ARAS method are as follows [3]:

Step 1: Determination of first decision matrix

$$
\mathrm{X}=\left[\begin{array}{ccccc}
x_{01} & \ldots & x_{0 j} & \ldots & x_{\text {on }} \\
\vdots & \cdots & \vdots & \cdots & \vdots \\
x_{i 1} & \ldots & x_{i j} & \ldots & x_{i n} \\
\vdots & \cdots & \vdots & \cdots & \vdots \\
x_{m 1} & \ldots & x_{m j} & \ldots & x_{m n}
\end{array}\right]
$$

Step 2: Determination of optimal performance ratings

$$
x_{\text {oj }}=\left\{\begin{array}{cc}
\max _{\tilde{F}} x_{i j} & j \in \Omega_{\max } \\
\operatorname{minx}_{\overline{f i j}} & j \in \Omega_{\min }
\end{array}\right.
$$

$x_{\text {oj }}$ is the best performance evaluation relating to $j^{\text {th }}$ criteria, $\Omega_{\max }$ symbolizes benefit criteria while $\Omega_{\min }$ symbolizes cost criteria.

Step3: Computation of the normalized decision matrix

$r_{i j}=\left\{\begin{array}{cl}\frac{x_{i j}}{\sum_{i=0}^{m} x_{i j}} & j \in \Omega_{\max } \\ \frac{\frac{1}{x_{i j}}}{\sum_{i=0}^{m} x_{i j}} j \in \Omega_{\min }\end{array}\right.$

where $r_{\mathrm{i} j}$ is the normalized performance degree of $i^{\text {th }}$ alternative as regards to $j^{\text {th }}$ criteria.

Step 4: Computation of weighted normalized decision matrix

$v_{i j}=w_{j} * r_{i j}, \quad i=1,2, \ldots \ldots m$

Step 5: Computation of total performance index for every alternative

$S_{i}=\sum_{j=1} v_{i j} i=0,1_{s} \ldots m$

Step 6: Computation the rate of closeness coefficient for each alternative

$Q_{\mathrm{i}}=S_{\mathrm{i}} /_{S_{0}} i=0,1_{x \ldots \ldots m}$

where $S_{0}$ is total performance index of the best alternative which is 1 generally. $Q_{i}$ refers to degree of utility of $i^{\text {th }}$ alternative.

Step 7: Ranking of alternatives and selection of best alternative The best alternative can be acquired by following formula:

$A^{*}=\left\{A_{i} \mid \max _{\tilde{i}} Q_{i}\right\}, \quad i=1,2 \ldots \ldots m$
Different researchers have implemented SAW method as it is simple. SAW method utilizes an easy aggregation process so that it can combine values and weights of criteria into a forecast parameter [10]. The steps of simple additive weighting method are as follows [13]:

Step 1: Normalization of decision matrix

We should convert original data into comparable values employing normalization technique. The step of normalization is as follows:

$r_{\mathrm{i} j}= \begin{cases}\frac{x_{i j}}{x_{j}^{\frac{4}{4}}} & j \in \Omega_{\max } \\ \frac{x_{j}^{-}}{x_{i j}} & j \in \Omega_{\min }\end{cases}$

where $r_{\mathrm{i} j}$ is the normalized value of the ith alternative for the jth criteria, $x_{j}^{+}$is the highest of $x_{i j}$ in the column of $\mathrm{j}$ for benefit criterion, $x_{j}^{-}$is the lowest of $x_{i j}$ in the column of $\mathrm{j}$ for cost criterion.

Step 2: Weighting of criteria

$\mathrm{W}=\left[w_{1}, w_{2}, \ldots, w_{n}\right]$

Step 3: Computation of ranking score

$S_{i}=\sum_{j=1}^{n} w_{j} x_{i j}$

where $S_{i}$ refers to ranking performance of the ith alternative, $w_{j}$ corresponds to weight of $j$ th criterion, $r_{\mathrm{i} j}$ is the normalized value of ith alternative, $S_{i}$ is the performance value in SAW method. The alternative with the maximum performance value takes the top rank.

\section{NUMERICAL ANALYSIS}

In this study, we adopt an integrated approach. In the first part of study, we calculate weights via Shannon entropy method. The weights of criterions are as attempts on target, accurate pass percentage, possession percentage and total goals respectively. We obtain the weights as follows:

$\mathrm{w}_{1}=0,25164$

$\mathrm{w}_{2}=0,22980$

$\mathrm{w}_{3}=0,33113$

$\mathrm{w}_{4}=0,18741$

After we determine the weights of criteria, we utilize additive ratio assessment (ARAS) method to determine ranking of World Cup teams in 2018. The results of ARAS method are illustrated in Table I.

\section{Simple additive weighting (SAW) Method}


TABLE I: ADDITIVE RATIO ASSESSMENT (ARAS) METHOD RESULTS FOR WORLD CUP 2018 TEAMS

\begin{tabular}{|c|c|c|}
\hline Ranking & Teams & Qi \\
\hline 1 & Belgium & 0,9344 \\
\hline 2 & Croatia & 0,8311 \\
\hline 3 & France & 0,7772 \\
\hline 4 & England & 0,7756 \\
\hline 5 & Brazil & 0,7596 \\
\hline 6 & Spain & 0,7026 \\
\hline 7 & Argentina & 0,5616 \\
\hline 8 & Uruguay & 0,5462 \\
\hline 9 & Russia & 0,5313 \\
\hline 10 & Germany & 0,5086 \\
\hline 11 & Japan & 0,5003 \\
\hline 12 & Switzerland & 0,4873 \\
\hline 13 & Portugal & 0,4785 \\
\hline 14 & Sweden & 0,4601 \\
\hline 15 & Colombia & 0,4465 \\
\hline 16 & Tunisia & 0,4205 \\
\hline 17 & Mexico & 0,4069 \\
\hline 18 & Saudi Arabia & 0,3924 \\
\hline 19 & Denmark & 0,3713 \\
\hline 20 & Peru & 0,3474 \\
\hline 21 & Senegal & 0,3442 \\
\hline 22 & Australia & 0,3367 \\
\hline 23 & Poland & 0,3332 \\
\hline 24 & Nigeria & 0,3287 \\
\hline 25 & Morocco & 0,3253 \\
\hline 26 & Korea Republic & 0,3093 \\
\hline 27 & Costa Rica & 0,2881 \\
\hline 28 & Serbia & 0,2876 \\
\hline 29 & Iceland & 0,2779 \\
\hline 30 & Egypt & 0,2765 \\
\hline 31 & Panama & 0,2762 \\
\hline 32 & Iran & 0,1965 \\
\hline
\end{tabular}

In the evaluated example, at first we adopt additive ratio assessment (ARAS) method. According to results of ARAS method, Belgium, Croatia and France are found as the top three teams. Besides, Egypt, Panama and Iran are found as the last three teams with the lowest ranking score.
In the second part of the study, we employ SAW method to rank alternatives. The results of SAW method are shown in Table II.

TABLE II: SIMPLE ADDITIVE WEIGHTING METHOD (SAW) METHOD RESULTS FOR WORLD CUP 2018 TEAMS

\begin{tabular}{|c|c|c|}
\hline Ranking & Teams & $\mathrm{Si}$ \\
\hline 1 & Belgium & 0,8760 \\
\hline 2 & Croatia & 0,7819 \\
\hline 3 & England & 0,7574 \\
\hline 4 & France & 0,7024 \\
\hline 5 & Brazil & 0,6760 \\
\hline 6 & Spain & 0,6472 \\
\hline 7 & Uruguay & 0,4622 \\
\hline 8 & Argentina & 0,4620 \\
\hline 9 & Russia & 0,4289 \\
\hline 10 & Japan & 0,4121 \\
\hline 11 & Switzerland & 0,3979 \\
\hline 12 & Germany & 0,3937 \\
\hline 13 & Portugal & 0,3814 \\
\hline 14 & Sweden & 0,3592 \\
\hline 15 & Colombia & 0,3515 \\
\hline 16 & Mexico & 0,3115 \\
\hline 17 & Tunisia & 0,3043 \\
\hline 18 & Saudi Arabia & 0,2983 \\
\hline 19 & Denmark & 0,2963 \\
\hline 20 & Peru & 0,2449 \\
\hline 21 & Australia & 0,2425 \\
\hline 22 & Poland & 0,2386 \\
\hline 23 & Senegal & 0,2288 \\
\hline 24 & Nigeria & 0,2166 \\
\hline 25 & Morocco & 0,2154 \\
\hline 26 & Korea Republic & 0,2073 \\
\hline 27 & Costa Rica & 0,1957 \\
\hline 28 & Serbia & 0,1952 \\
\hline 29 & Panama & 0,1911 \\
\hline
\end{tabular}




$\begin{array}{lcc}30 & \text { Egypt } & 0,1880 \\ 31 & \text { Iceland } & 0,1793 \\ 32 & \text { Iran } & 0,1054\end{array}$

According to simple additive weighting (SAW) method results, Belgium and Croatia and England are the top three teams with the highest ranking score. Egypt, Iceland and Iran are the last three teams with the lowest ranking score.

\section{CONCLUSION}

Multi criteria decision making (MCDM) methods have been widely applied to many different areas. These methods are particularly logical when the problem has many conflicting criterions. Various decision criterions should be considered in analyzing the football teams. Therefore, MCDM methods are viable vehicles to evaluate football teams.

In this study, we adopt an integrated approach. We integrate SAW and ARAS methods with Shannon entropy method which is an objective method to weight criterions. We employ additive ratio assessment (ARAS) and simple additive weighting method (SAW) as they are simple to use out of MCDM methods. In the empirical example, we compare results of these methods. According to additive ratio assessment (ARAS) method results, Belgium, Croatia and titleholder France are found as the top three teams with the highest ranking score. Besides, according to simple additive weighting method (SAW) result Belgium, Croatia and titleholder France are found as the top three teams. We observe a remarkable harmony between ARAS and SAW methods. As a result, the results of this study are generally in line with FIFA World Ranking and 2018 World Cup results.

We may conclude that this study can provide significant results for both officials and individual decision makers.

\section{REFERENCES}

[1] Dahooie, J. H., Zavadskas, E. K., Firoozfar, H. R., (2019). “An improved fuzzy MULTIMOORA approach for multi-criteria decision-making based on objective weighting method (CCSD) and its application to technological forecasting method selection". Engineering Applications of Artificial Intelligence, vol.79, pp. 114-128. https://doi.org/10.1016/j.engappai.2018.12.008

[2] dos Santos, B. M., Godoy, L. P., and Campos, L. M. (2019). "Performance evaluation of green suppliers using entropy-TOPSIS-F". Journal of cleaner production, vol.207, pp.498-509. https://doi.org/10.1016/j.jclepro.2018.09.235

[3] Fu, Y. K. (2019). "An integrated approach to catering supplier selection using AHP-ARAS-MCGP methodology". Journal of Air Transport Management, vol.75, pp.164-169. https://doi.org/10.1016/j.jairtraman.2019.01.011

[4] Jati, H., and Dominic, D. D. (2017). "A New Approach of Indonesian University Webometrics Ranking Using Entropy and PROMETHEE II". Procedia Computer Science, vol. 124, pp.444-451. https://doi.org/10.1016/j.procs.2017.12.176

[5] Karagiannis, R., and Karagiannis, G. (2019). Constructing composite indicators with Shannon entropy: The case of Human Development Index. Socio-Economic Planning Sciences. https://doi.org/10.1016/j.seps.2019.03.007
[6] Kutut, V., Zavadskas, E. K., and Lazauskas, M. (2013). “Assessment of priority options for preservation of historic city centre buildings using MCDM (ARAS)". Procedia Engineering, vol.57, pp. 657-661. https://doi.org/10.1016/j.proeng.2013.04.083

[7] Liu, S., Chan, F. T., and Ran, W. (2016). "Decision making for the selection of cloud vendor: An improved approach under group decision-making with integrated weights and objective/subjective attributes". Expert Systems with Applications, vol.55, pp.37-47. https://doi.org/10.1016/j.eswa.2016.01.059

[8] Mavi, R. K., Goh, M., and Mavi, N. K. (2016).” Supplier selection with Shannon entropy and fuzzy TOPSIS in the context of supply chain risk management". Procedia-Social and Behavioral Sciences, vol.235, pp.216-225.

https://doi.org/10.1016/j.sbspro.2016.11.017

[9] Qader, M. A., Zaidan, B. B., Zaidan, A. A., Ali, S. K., Kamaluddin, M. A., and Radzi, W. B. (2017)." A methodology for football players' selection problem based on multi-measurements criteria analysis". Measurement, vol. 111, pp.38-50. https://doi.org/10.1016/j.measurement.2017.07.024

[10] Serrai, W., Abdelli, A., Mokdad, L., and Hammal, Y. (2017). "Towards an efficient and a more accurate web service selection using MCDM methods". Journal of computational science, vol. 22, pp. 253-267. https://doi.org/10.1016/j.jocs.2017.05.024

[11] Shakouri, H., Nabaee, M.,and Aliakbarisani, S. (2014). "A quantitative discussion on the assessment of power supply technologies: DEA (data envelopment analysis) and SAW (simple additive weighting) as complementary methods for the "Grammar". Energy, vol. 64, pp.640-647. https://doi.org/10.1016/j.energy.2013.10.022

[12] Wang, E., Alp, N., Shi, J., Wang, C., Zhang, X., and Chen, H. (2017). "Multi-criteria building energy performance benchmarking through variable clustering based compromise TOPSIS with objective entropy weighting". Energy, vol. 125, pp.197-210. https://doi.org/10.1016/j.energy.2017.02.131

[13] Wang, P., Zhu, Z., and Wang, Y. (2016). "A novel hybrid MCDM model combining the SAW, TOPSIS and GRA methods based on experimental design". Information Sciences, vol.345, pp.27-45. https://doi.org/10.1016/j.ins.2016.01.076

[14] Zavadskas, E. K., and Turskis, Z. (2010). "A new additive ratio assessment (ARAS) method in multi criteria decision making". Technological and Economic Development of Economy, vol.16 (2), pp.159-172. https://doi.org/10.3846/tede.2010.10

[15] Zavadskas, E. K., Turskis, Z., and Vilutiene, T. (2010). "Multiple criteria analysis of foundation instalment alternatives by applying Additive Ratio Assessment (ARAS) method". Archives of civil and mechanical engineering, vol.10 (3), pp.123-141. https://doi.org/10.1016/S1644-9665(12)60141-1

[16] Zhang, H. Gu, C. L. Gu, L. W. and Zhang, Y. (2011). "The evaluation of tourism destination competitiveness by TOPSIS \& information entropy-A case in the Yangtze River Delta of China." Tourism Management, vol.32 (2), pp. 443-451.

https://doi.org/10.1016/j.tourman.2010.02.007 